\title{
Structure of mound-building ant settlements (genus Formica) in Kuzokotsky Peninsula (northern Karelia)
}

\author{
Alexander Markov ${ }^{1,2}$, Alexsey Gilev ${ }^{3}$, and Tatyana Putyatina ${ }^{1}$ \\ ${ }^{1} \mathrm{M}$. V. Lomonosov Moscow State University, Faculty of Biology, \\ Vorobjevy gory 1/12, Moscow 119991, Russian Federation \\ 2Institute of Psychology, Russian Academy of Sciences, \\ Yaroslavskaya ul. 13/1, Moscow 129366, Russian Federation; tsergput@gmail.com \\ 3 Institute of Plant and Animal Ecology, Ural Branch, Russian Academy of Sciences, \\ Eighth Mart 202, Yekaterinburg 620144, Russian Federation \\ Address correspondence and requests for materials to Tatyana Putyatina, tsergput@gmail.com
}

Citation: Markov, A., Gilev, A., and Putyatina, T. 2017. Structure of moundbuilding ant settlements (genus Formica) in Kuzokotsky Peninsula (northern Karelia). Bio. Comm. 62(2): 93-102. doi: 10.21638/11701/spbu03.2017.205

Author's information: Alexander Markov, Head of Department of Biological Evolution, Dr.Sci., Professor, orcid.org/00000002-7113-7181, Alexsey Gilev, Leading Researcher, Dr. Sci., orcid.org/0000-00020404-6343, Tatyana Putyatina, Senior Researcher, PhD, orcid.org/0000-0002-99835141

Manuscript Editor: Dr. Yegor Malashichev, Saint Petersburg State University, Russian Federation

Received: April 18, 2017;

Revised: August 18, 2017;

Accepted: August 24, 2017;

Copyright: (c) 2017 Markov et al. This is an open-access article distributed under the terms of the License Agreement with Saint Petersburg State University, which permits to the authors an unrestricted distribution and self-archiving free of charge.

Funding: This work was supported by the Russian Science Foundation (project No 14-28-00229)

Competing interests: The authors have declared that no competing interests exist.

\begin{abstract}
The spatial distribution of obligate dominant ant species, which includes four species of the genus Formica: F. exsecta, F. lugubris, F. aquilonia and F. uralensis, and differentiation of multispecies settlements has been studied in the eastern Kuzokotsky Peninsula (northern Karelia, Russia). F. exsecta and F. lugubris were present in remote single colonies, groups of two or three nests, single-species complexes of no more than ten nests, or larger multispecies settlements. F. aquilonia formed a small complex within one of the multispecies settlements. The nests of $F$. uralensis were single. Significant preference of $F$. exsecta to aggregate with $F$. lugubris was revealed in two permanent multispecies settlements; such a preference is atypical for these species in other areas. The nests of $F$. aquilonia were aggregated only with the nests of their own species. Presumably, the settlement of $F$. lugubris was facilitated by capturing the active nests of $F$. exsecta. This is confirmed by the reported case of capture of one F. exsecta nest by an adjacent colony of $F$. lugubris, as well as by similar cases repeatedly described by other authors. The change of the host species did not violate the spatial structure of the settlement. Thus, a unique structure of settlements of obligate dominant ant species with complicated interactions among them has been described in northern Karelia.
\end{abstract}

Keywords: Ants, multispecies settlements, obligate dominant, F. exsecta, F. lugubris, F. aquilonia, F. uralensis, Karelia.

Traditionally, the invertebrates of the forests of central and southern Europe have been much better studied than those of the forests of northern Europe, and this applies to ants as well (Domisch et al., 2005; Kilpelainen et al., 2005). Yet, even in northern conditions, ants prevail by biomass among invertebrates. Therefore, in the northeastern part of the Russian Federation, namely in Upper Kolyma, ants dominate in absolute numbers (Berman et al., 2010). They act as predators, seed and honeydew consumers, and take an active part in soil-forming processes (Gorb and Gorb, 1999; Frouz et al., 2008). They are also a source of food for many animals. Due to all the above mentioned factors ants can be considered as one of the key groups of insects in European forests (Dlussky, 1967; Hölldobler and Wilson, 1990, 2008).

Ants live in multispecies communities. Species in such communities are closely connected by different types of interactions, from competitive to mutualistic ones, and usually form a three-level behavioral hierarchical structure of dominant-subdominant-influent (Reznikova, 1983; Vepsäläinen and Savolainen, 1990; Zakharov, 2011a). When mound-building ant species are present in these 
communities they are generally obligate dominants due to their large number and social organization. As dominant species they control the living conditions of other members of the community and organize its spatiotemporal structure. Therefore, it is advisable to begin the study of ant communities of northern Europe with obligate dominants.

Obligate dominant ant species of the northern European forests include the following representatives of the genus Formica: the Formica rufa group, F.pratensis Retz., F.truncorum F., F.exsecta Nyl., and F.uralensis Ruzsky (Czechowski et al., 2002). All these species are mound-building ants, which form complex nests with an epigenous dome (Dlussky, 1967; Zakharov, 2015). The settlements of red wood ants (Formica rufa group) are the best studied (Pamilo et al., 1992; Czechowski and Radchenko, 2006; Zakharov, 2015) while those of F. exsecta have been studied only lately (Pisarski, 1982; Goryunov, 2007, 2011). Sociotomy (budding and fragmentation) is a characteristic feature in all these species, which explains why they often form large compact settlements. Red wood ants, as a result of budding, form long-lasting polycalic colonies - groups of nests, maternal and daughter, connected by exchange routes (Gösswald, 1978; Cherix, 1980; Zakharov, 1991).

The spatial organization of the settlements of obligate dominant ants in northern Europe has been poorly investigated. This could be of interest since the biological and ecological features of the ant populations of northern Europe often differ greatly from the central European ones (Berman et al., 2010). Our work is devoted to the analysis of the spatial distribution of moundbuilding ants in the north of Europe. For this purpose, the eastern part of the Kuzokotsky Peninsula, located in the north of the Republic of Karelia in the Russian Federation $\left(35 \mathrm{~km}\right.$ northeast of the town of Chupa, $66.5^{\circ} \mathrm{N}$, $\left.33.6^{\circ} \mathrm{E}\right)$, was surveyed.

\section{Materials and methods}

In July and August 2014 we recorded, mapped, and described by standard methods (Zakharov et al., 2013) all nests of Formica ants located in the eastern part of the Kuzokotsky Peninsula on the White Sea coast. The total examined area covers 400 ha. In July and August 2015 we made a second inventory of the three large settlements, "Cape", "Pink Rocks" and "Kuzyaki" (Fig. 1).

Four types of biotopes were present in the studied area: rocks with isolated "islands" of shrubs and coniferous trees, coastal crowberry beds, raised bogs, and forests with high canopy projection area. In the forests (mixed forests of birch, pine and pine-spruce), which occupy most of the peninsula, we did not find any nests of mound-building ants. The nests of most species were located either on the rocks or in the coastal crowberry beds.
In addition to measuring the dimensions of the nests, the length of the foraging routes was measured for the species F.lugubris, and the distances between all nests were recorded with an accuracy of up to $1 \mathrm{~m}$. The diameter and height of the mounds were used to compare the nests. In both 2014 and 2015 we monitored the damage done to ant nests by bears; in 2015 the state of the nests was monitored during the entire study period.

In the "Cape" settlement and the central part of the "Pink Rocks" settlement a "sugar shooting" experiment was performed to compare the size of F.exsecta and F. lugubris foraging areas. For this purpose, we chose six nests of each species (three pairs of F. exsecta-F. lugubris in each of two settlements) of the closest neighbour nests. Then, along the line connecting the nests of the same pair, sugar feeders (cotton wool soaked in a sugar syrup poured on a plastic surface) were placed at a distance of 1-5 $\mathrm{m}$ from each other ( $1 \mathrm{~m}$ for the first five feeders and 3-5 $\mathrm{m}$ for the subsequent ones). The feeders were exposed for 2-3 hours. During this time, the number of ants present on the feeders was registered four times. The nest of origin of the ants was determined by following them back to their nests. The experiment was carried out in sunny weather at a temperature varying between 16 to $20^{\circ} \mathrm{C}$. The mounds of F. lugubris were 80-95 cm in diameter, except for nest 6a (Fig. 3) which had a mound of $60 \mathrm{~cm}$ in diameter. The similar sizes of the nests of F. exsecta from each settlement were chosen (two small, $\mathrm{d}=40-60 \mathrm{~cm}$, and one large, $\mathrm{d}>85 \mathrm{~cm}$, nest).

The taxonomic identification of the ants was achieved by the authors according to the keys provided by Dlussky (1967). The specimens collected are stored at the Department of Biological Evolution of the M. V.Lomonosov Moscow State University.

The statistical analysis of the results was carried out using the Mann-Whitney test for two independent samples, the Kruskall-Wallis test for multiple sample comparisons and the Clark-Evans test (Clark and Evans, 1954). We tested the following hypotheses: 1 ) whether there are differences between ant species in the parameters studied, and 2) whether there are the same differences between the settlements' species (it is important for the settlements structure analysis). All calculations were performed with Microsoft Excel 2003 and Statistica v. 6.0 (StatSoft, Ink., 1984-2001).

\section{Results}

In the eastern part of the Kuzokotsky Peninsula, we found 75 nests of mound-building ants belonging to four species: Formica exsecta, F.lugubris, F.aquilonia, and F. uralensis (Fig. 1, Table 1). F. uralensis was found only on raised bogs. The main obligate dominants $(85.3 \%$ of the nests) in the studied area were F. exsecta and F. lugubris, to which one can add F. aquilonia in the eastern part 


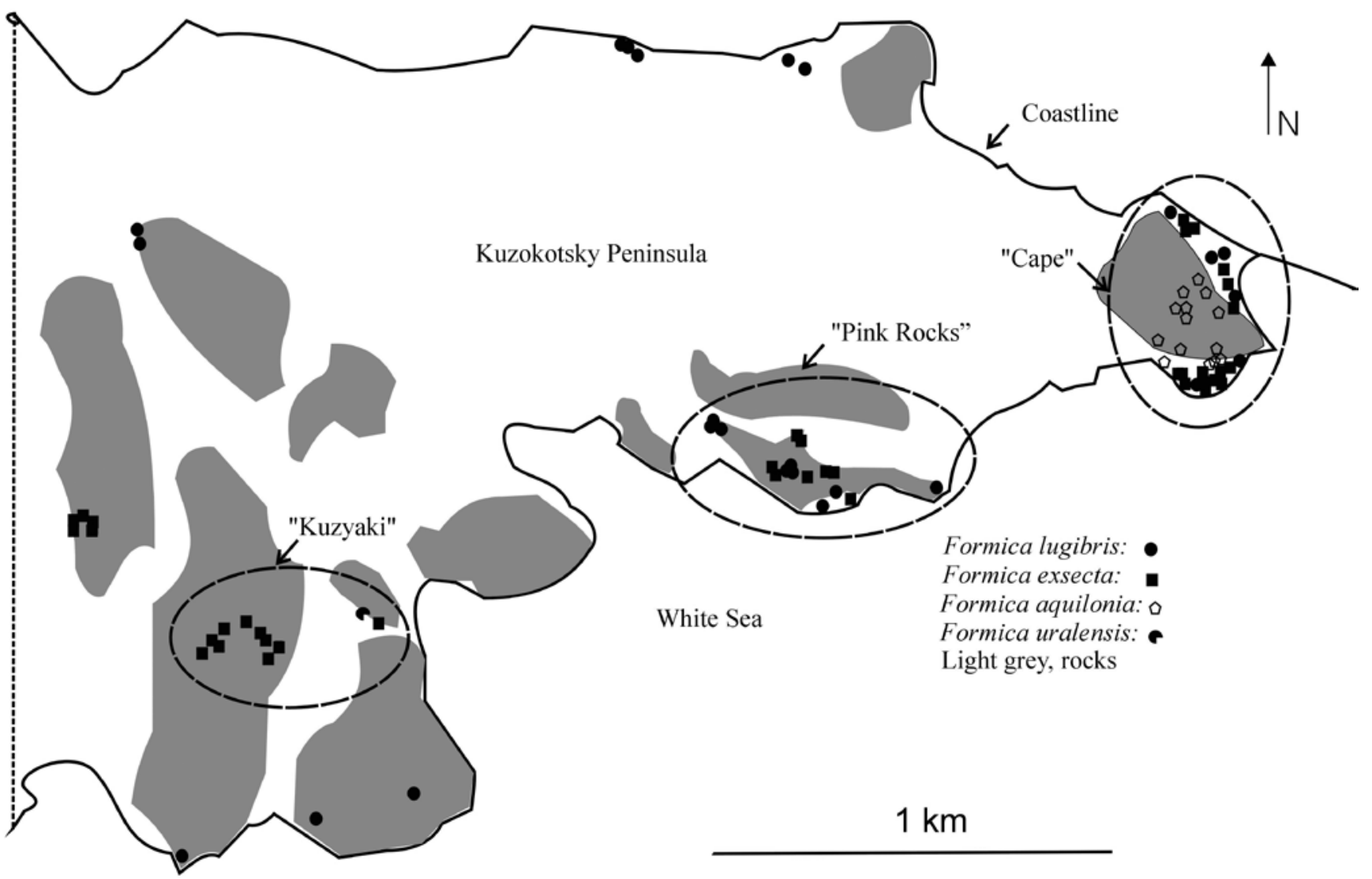

Fig. 1. Location of Formica nests in the eastern part of the Kuzokotsky Peninsula, 2015

Table 1. Main characteristics of Formica nests in the Kuzokotsky Peninsula

\begin{tabular}{l|l|c|c|c}
\hline \multicolumn{1}{c|}{ Type of disposition } & \multicolumn{1}{|c|}{ Species } & N & D & H \\
\hline «Pink Rocks» & F. exsecta & 8 & $61.3 \pm 6.60$ & $27.5 \pm 3.27$ \\
settlement & F. lugubris & 10 & $75.5 \pm 5.60$ & $27.3 \pm 4.30$ \\
\hline The central part of the & F. exsecta & 7 & $63.3 \pm 8.72$ & $30.8 \pm 3.27$ \\
"Pink Rocks" settlement & F. lugubris & 8 & $71.7 \pm 9.10$ & $32.2 \pm 6.06$ \\
\hline \multirow{3}{*}{ The "Cape" settlement } & F. exsecta & 15 & $68.0 \pm 8.31$ & $19.7 \pm 1.14$ \\
& F. lugubris & 6 & $75.8 \pm 10.28$ & $22.5 \pm 4.79$ \\
& F. aquilonia & 10 & $61.3 \pm 7.95$ & $21.3 \pm 2.80$ \\
\hline The "Kuzyaki" & F. exsecta & 10 & $64.5 \pm 5.24$ & $29.7 \pm 2.81$ \\
settlement & F. uralensis & 1 & 30 & 15 \\
\hline Single nests and small & F. exsecta & 5 & $69.0 \pm 10.54$ & $25.0 \pm 2.24$ \\
groups of nests & F. lugubris & 10 & $78.0 \pm 13.00$ & $23.5 \pm 3.66$ \\
\hline
\end{tabular}

$\mathrm{N}$, number of nests; $\mathrm{D}$, mound diameter in $\mathrm{cm}$ (mean $\pm \mathrm{SE}) ; \mathrm{H}$, mound height in $\mathrm{cm}$ (mean $\pm \mathrm{SE})$.

of the peninsula (Fig. 1, Table 1). The number of F. exsecta nests (38) is practically equal to the total number of nests of other mound-building species (37).

Most anthills (78\%) were concentrated in three multispecies settlements (Fig. 1), located about $1 \mathrm{~km}$ apart. The remaining nests, i.e. 10 nests of F. lugubris that stand as single nests or as two to three nest alignments, and a group of five F.exsecta nests, were more distant from the main clusters.

\section{MULTISPECIES SETTLEMENTS OF OBLIGATE DOMINANTS}

The three multispecies settlements of the peninsula differed in species composition.

In the late July of 2015, the "Kuzyaki" settlement, situated in the southwestern part of the studied area, consisted of 10 F. exsecta nests located on the rocks. The only nest of obligate dominants in the vicinity was a rather small nest of F. uralensis the mound of which was $30 \mathrm{~cm}$ in diameter, situated at the outskirts of a raised bog ( $12 \mathrm{~m}$ from an average size nest of F.exsecta). In the late summer of 2014 this settlement contained two nests of F. lugubris. However, these two nests disappeared in 2015. In the settlements "Pink Rocks" and "Cape" on the other hand, all the nests mapped in 2014 were present in 2015, and several new nests appeared.

The largest settlement, "Cape" is situated in the easternmost part of the peninsula, in a coastal area with strong winds (Fig. 1). It included 31 nests of three species: F. exsecta, F. lugubris, and F.aquilonia (Table 1). F.aquilonia kept away from the other species and formed a complex situated mostly in rocky places, adjacent to the groups of nests of F. lugubris and F. exsecta located in the coastal crowberry bed (Fig. 2). In 2015 we did not check for the presence of the three most remote located nests 


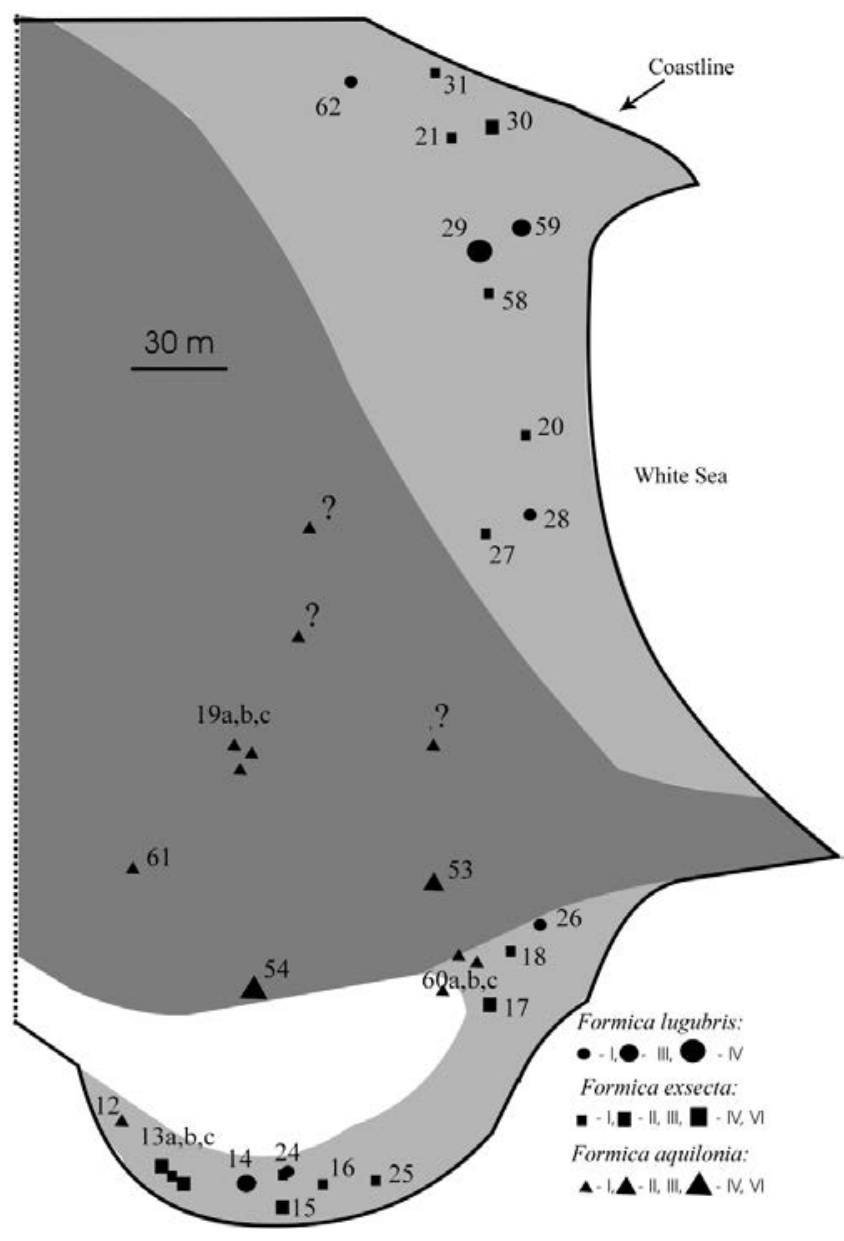

Fig. 2. Nest location in the "Cape" settlement

Biotopes: white, mixed forest; dark gray, rocks with shrubs and coniferous trees; light grey, coastal crowberry beds; (?) presence of nests was not checked in 2015. Mound diameter: (I) $\leq 60 \mathrm{~cm}$; (II) $65-80 \mathrm{~cm}$; (III) $85-100 \mathrm{~cm}$; (IV) 105-120 cm; (VI) $>140 \mathrm{~cm}$.

of F.aquilonia because they were difficult to access. The ten nests of F. aquilonia examined included two groups of three nests and four separately standing nests (Fig. 2).

The "Pink Rocks" settlement, situated in the southeastern part of the peninsula, consisted of 18 nests of F. lugubris and F. exsecta, with an almost equal number of nests for each species (Table 1). Fifteen of these nests were

Table 2. Proportion of nests damaged by bears (Ursus arctos)

\begin{tabular}{l|l|c|c|c|c}
\hline \multirow{2}{*}{ Settlement } & \multirow{2}{*}{ Species } & \multicolumn{3}{|c|}{ Period of damaging } & \multirow{2}{*}{\begin{tabular}{c} 
Over all \\
\cline { 3 - 5 }
\end{tabular}} \\
\cline { 3 - 5 } & $\begin{array}{c}\text { July, } \\
\text { Aug. } \\
\mathbf{2 0 1 4}\end{array}$ & $\begin{array}{c}\text { Sept. } \\
\mathbf{2 0 1 4}- \\
\text { June 2015 }\end{array}$ & $\begin{array}{c}\text { July, } \\
\text { Aug. } \\
\text { 2015 }\end{array}$ & $\begin{array}{c}\mathbf{2 0 1} \\
\text { together }\end{array}$ \\
\hline «Pink & F. exsecta & 0.00 & 0.25 & 0.00 & 0.25 \\
Rocks» & F. lugubris & 0.10 & 0.40 & 0.20 & 0.40 \\
\hline \multirow{3}{*}{ «Cape» } & F. exsecta & 0.14 & 0.07 & $0.46^{b}$ & 0.60 \\
& F. lugubris & 0.00 & 0.40 & $0.40^{b}$ & 0.80 \\
& F. aquilonia & 0.00 & 0.14 & 0.14 & 0.14 \\
\hline \multirow{2}{*}{ «Kuzyaki» } & F. exsecta & 0.00 & 0.50 & 0.00 & 0.50 \\
& F. uralensis & 0.00 & 1.00 & 0.00 & 1.00 \\
\hline
\end{tabular}

${ }^{a}$ One colony may have been damaged several times.

b About $20 \%$ of the colonies during this period were destroyed twice. situated on the rocky outcrops, two on the outskirts of a raised bog and one in the coastal crowberry beds. All the biotopes were occupied by nests of both species (Fig. 3).

Six of the 10 nests of F. lugubris were situated in two groups of three nests each.

All ant settlements were regularly and strongly damaged by bears (Table 2). The same nest could be destroyed in the first (July and August 2014), the second (September, 2014 - June, 2015) or the third (July and August 2015) study periods. We consider July and August separately, because they are the most favourable months for the ants' colonies development.

\section{SIZE OF FORMICA NESTS}

The average size of the nests in the studied area is shown in Table 1. Two flat nests of F. lugubris in the settlement "Cape" were excluded. F. lugubris and F. exsecta nests, located singly or in small groups, have typically the largest size. The nests in the settlement "Pink Rocks" have the smallest diameters. The lowest nests are found in the settlement "Cape". The size of the foraging area, as well as the distance to the nearest neighbor, can depend on the size of the nest. Since the sizes of the nests seemed different between settlements, we decided to check to what extent the differences were significant. To compare the diameter and height of the mounds of F.lugubris and F. exsecta between settlements, a Kruskall-Wallis test was used (Table 3). Significant differences were noted only for F. exsecta in the height of the nests. This is due to the smaller size of the nests of this species in the "Cape" settlement (Fig. 4). Thus, in the "Cape" settlement, with almost equal diameters, the nests are the flattest in comparison with the nests in the other settlements.

Table 3. Comparison of mound size with the Kruskall-Wallis test

\begin{tabular}{l|l|l}
\hline \multicolumn{1}{c|}{ Species } & \multicolumn{1}{c|}{ Diameter $(\mathbf{c m})$} & \multicolumn{1}{c}{ Height $(\mathbf{c m})$} \\
\hline F. lugubris & $\mathrm{H}=0.22, \mathrm{p}=0.897$ & $\mathrm{H}=0.39, \mathrm{p}=0.822$ \\
F. exsecta & $\mathrm{H}=0.91, \mathrm{p}=0.820$ & $\mathrm{H}=11.23, \mathrm{p}=0.011$ \\
\hline
\end{tabular}

$\mathrm{H}$ - statistics value, $\mathrm{p}-$ associated probability

The sizes of F. lugubris nests in different settlements almost did not differ, although in the "Pink Rocks" settlement there is a tendency for the nests to be larger. The sizes of the nests of F.aquilonia are slightly larger than those of F.lugubris, either when comparing across all settlements, or when comparing for the settlement "Cape" only.

\section{RELATIVE POSITION OF OBLIGATE DOMINANTS IN THE SETTLEMENTS}

F. exsecta and F. lugubris were found together in all the three major peninsula settlements in 2014 and in two of them in 2015. Since the two settlements "Pink Rocks" 


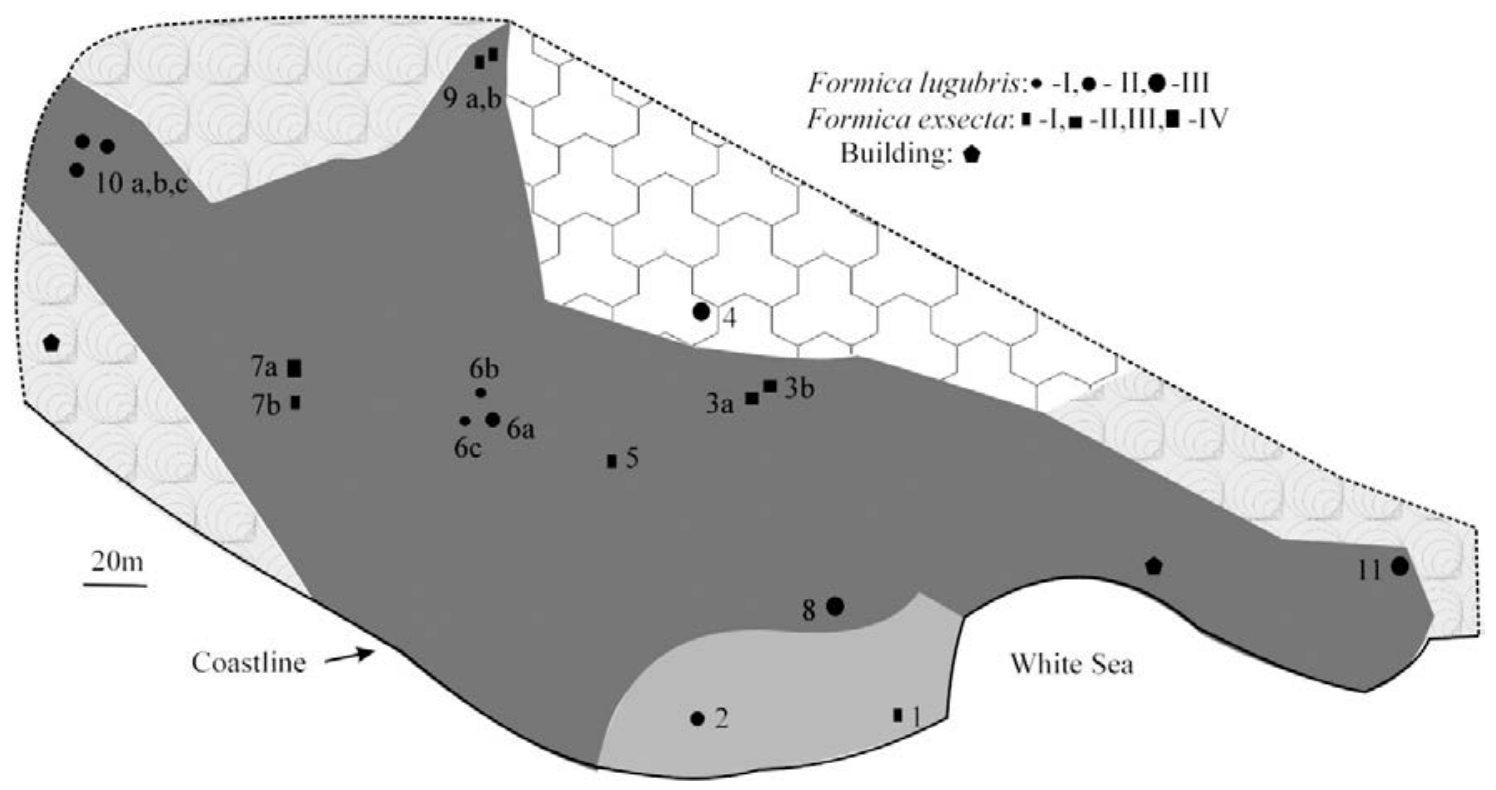

Fig. 3. Nest location in the "Pink Rocks" settlement

Biotopes: squares on grey background, pine forest; waves on white backgound, wetland; dark grey, rocks with shrubs and coniferous trees; light grey, coastal crowberry beds. Mound diameter: (I) $\leq 60 \mathrm{~cm}$; (II) $65-80 \mathrm{~cm}$; (III) $85-100 \mathrm{~cm}$; (IV) $105-120 \mathrm{~cm} ;(\mathrm{VI})>140 \mathrm{~cm}$.

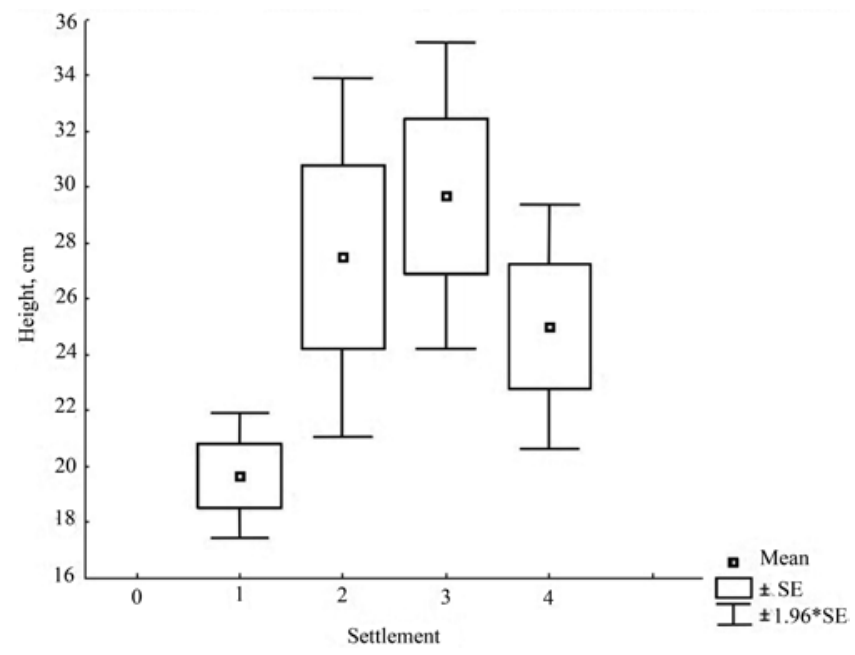

Fig. 4. Average height of the nests

Settlements: 1 - the "Cape" settlement, 2 - the "Pink Rocks" settlement, 3 - The "Kuzyaki" settlement, 4 - Single nests and small groups of nests.

and "Cape" presented a higher species diversity than the "Kuzyaki" settlement, we analyze these settlements in more details below.

From the maps of the settlements "Pink Rocks" and "Cape" it can be seen that colonies and groups of two to three nests of F. exsecta and F. lugubris were not isolated, but often joined together, forming mixed settlements. This tendency for the nests of two species to settle close to each other can be contingently called "xenophilia".

To analyze the spatial structure of the settlements and identify a possible tendency to "xenophilia" the minimum distance to conspecific and heterospecific nests were estimated for each nest, as well as the distance to the nearest neighbour nest without taking into account its species affiliation. The average values of these distances for each settlement are given in Table 4.

Quantitative evaluation of "xenophilia" was carried out only for F. exsecta and F. lugubris colonies. There were no other obligate dominants in the settlements. The colonies of $F$. aquilonia present in the "Cape" settlement were ignored, because they formed a compact cluster and clearly showed no trend towards xenophilia (Fig. 2). The average distance to the nearest neighbor nest could coincide with the average distance to conspecific or heterospecific nest only if the nearest neighbor was either a conspecific or a heterospecific nest. Such cases are presented in Table 4 (for example, F. lugubris, the "Cape" settlement). In other cases, when the nearest neighbor turned out to be a conspecific or a heterospecific nest, the average distance value to the nearest neighbor nest

Table 4. Distances in meters (mean $\pm S E$ ) between nests in two of the ant settlements of the Kuzokotsky Peninsula

\begin{tabular}{l|l|c|c|c}
\hline Settlement & Species & $\begin{array}{c}\text { Conspecific } \\
\text { nests }\end{array}$ & $\begin{array}{c}\text { Hetero- } \\
\text { specific nests }\end{array}$ & $\begin{array}{c}\text { Nearest } \\
\text { neighbours }\end{array}$ \\
\hline $\begin{array}{l}\text { The «Cape» } \\
\text { settlement }\end{array}$ & F. lugubris & $93.60 \pm 10.56$ & $16.20 \pm 3.01$ & $16.20 \pm 3.01$ \\
\hline F. exsecta & $22.40 \pm 3.04$ & $24.58 \pm 2.89$ & $16.00 \pm 1.17$ \\
\hline $\begin{array}{l}\text { Rocks» } \\
\text { settlement }\end{array}$ & F. lugubris & $97.00 \pm 24.55$ & $71.20 \pm 20.64$ & $69.20 \pm 20.91$ \\
\hline $\begin{array}{l}\text { The central } \\
\text { part of the } \\
\text { «Pink Rocks» } \\
\text { settlement }\end{array}$ & F. lugubris & $60.00 \pm 5.77$ & $41.80 \pm 7.05$ & $38.80 \pm 4.27$ \\
\hline
\end{tabular}


was different from the average distance to conspecific or heterospecific nests.

In addition, in the settlement "Pink Rocks", the central fragment of the settlement was considered separately, without the nests 9,10 and 11 , which were at least $100 \mathrm{~m}$ away from it (Fig. 3). The nests were considered belonging to the same aggregation (colony or group) if they were connected by inter-nest routes or located at a distance of no more than $10 \mathrm{~m}$ from each other. Nest number 24 in the "Cape" settlement was not taken into account in the calculations, because during the observation period it was first a nest of F. exsecta, and then was captured by F. lugubris.

Practically all calculated distances appeared to be different between settlements (Table 4), which could suggest that the spatial organization of the settlements is also different. Table 5 shows that practically all calculated distances were significantly different between the two settlements. The only exception was the difference in the distances of conspecific nests for F.lugubris, but these latter became significant when comparing the settlement "Cape" and the central part of the "Pink Rocks" settlement. As can be seen on Table 4, all the distances in the "Pink Rocks" settlement were greater than those in the "Cape" settlement. However, in the central part of the "Pink Rocks" settlement the average distance between the nests of F. lugubris was shorter than in the "Cape" settlement. All these, point to a different spatial organization of the nests in the two settlements, which justifies considering them separately in the following analysis.

The analysis of the difference between the distances of conspecific and heterospecific nests shows that for F. lugubris these distances are different only in the "Cape" settlement (Table 6). The distances of the nests of $F$. lugubris to those of $F$. exsecta were significantly shorter than to those of homospecific nests (Table 4). This may indicate a tendency of F. lugubris to settle next to F. exsec$t a$. At the same time, such differences were not found for F. exsecta, showing that this species has no obvious preference to settle either closer to a nest of its own species or to a nest of another species (Tables 4, 6).

In the settlement "Pink Rocks", for both species, the average distance to conspecific nests was a little higher than that to heterospecific nests, but the differences were not significant. This was also true for the central part of the settlement. Thus, in this settlement there are no clear preferences for a species to settle next to its own or to another species, although it can nevertheless be said that there is a tendency to this.

The difference between settlements in average distance to the nearest neighbor nest for F. lugubris and F.exsecta, without taking into account the species affiliation, was also estimated. For both species, these distances were shorter than the average distances to homospecific or heterospecific nests. The differences between species for
Table 5. Test of differences between settlements in the distances to conspecific, heterospecific and nearest neighbor nest (Mann-Whitney test).

\begin{tabular}{l|c|c|c}
\hline Species & $\begin{array}{c}\text { Conspecific } \\
\text { nests }\end{array}$ & $\begin{array}{c}\text { Heterospecific } \\
\text { nests }\end{array}$ & $\begin{array}{c}\text { Nearest } \\
\text { neighbours }\end{array}$ \\
\hline \multicolumn{4}{c}{ The "Cape" and "Pink Rocks" settlements } \\
\hline F. lugubris & $\mathrm{Z}=0.92, \mathrm{p}=0.357$ & $\mathrm{Z}=2.75, \mathrm{p}=0.006$ & $\mathrm{Z}=2.75, \mathrm{p}=0.006$ \\
F. exsecta & $\mathrm{Z}=3.07, \mathrm{p}=0.002$ & $\mathrm{Z}=2.48, \mathrm{p}=0.013$ & $\mathrm{Z}=3.17, \mathrm{p}=0.002$ \\
\hline \multicolumn{4}{c}{ The "Cape" settlement and the central part of } \\
the «Pink Rocks» settlement \\
\hline F. lugubris & $\mathrm{Z}=2.49, \mathrm{p}=0.013$ & $\mathrm{Z}=2.46, \mathrm{p}=0.014$ & $\mathrm{Z}=2.46, \mathrm{p}=0.014$ \\
F. exsecta & $\mathrm{Z}=2.81, \mathrm{p}=0.005$ & $\mathrm{Z}=2.13, \mathrm{p}=0.033$ & $\mathrm{Z}=2.92, \mathrm{p}=0.003$ \\
\hline
\end{tabular}

$\mathrm{Z}$ - statistics value, $\mathrm{p}-$ associated probability

Table 6. Test of differences in average distance to conspecific and heterospecific nearest neighbour nests for each species and each settlement (Mann-Whitney test)

\begin{tabular}{l|l|l}
\hline \multicolumn{1}{c|}{ Settlement } & \multicolumn{1}{c|}{ Species } & Criterion value \\
\hline \multirow{2}{*}{ The "Cape" settlement } & F. lugubris & $\mathrm{Z}=2.63, \mathrm{p}=0.008$ \\
& F. exsecta & $\mathrm{Z}=0.35, \mathrm{p}=0.729$ \\
\hline \multirow{2}{*}{ The "Pink Rocks" settlement } & F. lugubris & $\mathrm{Z}=1.13, \mathrm{p}=0.261$ \\
& F. exsecta & $\mathrm{Z}=1.57, \mathrm{p}=0.116$ \\
\hline The central part of the "Pink Rocks» & F. lugubris & $\mathrm{Z}=1.75, \mathrm{p}=0.080$ \\
settlement & F. exsecta & $\mathrm{Z}=1.74, \mathrm{p}=0.081$ \\
\hline
\end{tabular}

$\mathrm{Z}$ - statistics value, $\mathrm{p}$ - associated probability

Table 7. Comparison of average distances to nearest neighbour between species in each settlement (Mann-Whitney test)

\begin{tabular}{l|l}
\hline \multicolumn{1}{c|}{ Settlement } & Criterion value \\
\hline The «Cape» settlement & $Z=0.53, p=0.593$ \\
The «Pink Rocks» settlement & $Z=0.46, p=0.644$ \\
The central part of the «Pink Rocks» settlement & $Z=0.00, p=1.000$ \\
\hline
\end{tabular}

$\mathrm{Z}$ - statistics value, $\mathrm{p}$ - associated probability

Table 8. Radius in meters (mean $\pm \mathrm{SE}$ ) of the foraging area of Formica species in the settlement "Pink Rocks" and "Cape".

\begin{tabular}{l|c|c}
\hline \multicolumn{1}{c|}{ Species } & $\begin{array}{c}\text { The central part of the } \\
\text { «Pink Rocks» settlement }\end{array}$ & $\begin{array}{c}\text { The «Cape» } \\
\text { settlement }\end{array}$ \\
\hline F. exsecta & $2.7 .0 \pm 0.9$ & $2.1 \pm 1.7$ \\
F. lugubris & $32.0 \pm 3.5$ & $10.3 \pm 4.3$ \\
\hline
\end{tabular}

each settlement taken separately were not significant (Tables 4,7$)$. This means that a nest's nearest neighbor can be equally likely homo- or heterospecific. The distances between the closest colonies (or groups) of obligate dominants in the two settlements differed significantly and were about $16 \mathrm{~m}$ for the "Cape" and $38.8 \mathrm{~m}$ for the central part of the "Pink Rocks" settlement.

To determine the nests' distribution pattern in the settlements we applied the Clark-Evans test (Clark and Evans, 1954). The F. lugubris and F. exsecta nest distribution in the "Pink Rocks" settlement was significantly different from random and tended towards a uniform distribution $(\mathrm{R}=1.817, \mathrm{Z}=5.189, \mathrm{p}<0.001)$, while it was significantly clustered for the same species in the "Cape" settlement $(R=0.558, Z=3.688, p<0.010)$. 


\section{USAGE OF FORAGING AREAS}

The size of foraging areas (FA) in ants can be assessed both by the distance of individual foragers from their nest and by the length of the foraging routes departing from the nest. However, this can be done only for F. lugubris since F. exsecta do not use foraging routes. The number and length of foraging routes of F. lugubris were different between the two settlements. In the "Cape" settlement three nests out of six had foraging routes. These were nests 62, 29 and 14 with one, five and four routes, respectively. Their average length was $4.3 \pm 1.2 \mathrm{~m}$ (mean $\pm \mathrm{SE}$ ). In the central part of the settlement "Pink Rocks", three out of six nests also had foraging routes. These were the nests $6 \mathrm{a}, 6 \mathrm{~b}$ and 8 with two, one and five routes, respectively. Their average length was higher than in the "Cape" settlement and was $12.2 \pm 3.5 \mathrm{~m}$ (mean $\pm \mathrm{SE}$ ).

The radii of $\mathrm{FA}$, estimated from the observations with the "sugar shooting" experiments, differed significantly ( $\mathrm{Z}=2.33, \mathrm{p}=0.020)$ between the two species. In F. exsecta they did not exceed three meters, while in F. lugubris they could reach tens of meters (Table 8). The radii of FA in F.exsecta in both settlements were similar, their differences were not significant. At the same time, in F. lugubris in the "Cape" settlement the radii of FA were significantly shorter $(Z=1.96, p=0.049)$ (Table 8$)$.

\section{CAPTURING THE NEST}

To explain the spatial organization of settlements of obligate dominants in our study area, the observations made in August 2015 in the settlement "Cape" are essential.

The large colony of F. lugubris number $14(\mathrm{~d}=$ $85 \mathrm{~cm}$ ) was located between two colonies of F.exsecta. On one of its sides, it had as neighbour colony 13, which consisted of three nests, while on the other side it had as neighbors nest $15(\mathrm{~d}=70 \mathrm{~cm})$ and a small nest $24(\mathrm{~d}=$ $45 \mathrm{~cm}$ ) (Fig. 2). Under these conditions, the F.lugubris colony invaded nest 24, owned by F. exsecta. We discovered these three days later, when only workers of F. lugubris were found in nest 24, and all workers of F.exsecta had disappeared.

\section{Discussion}

The distribution of obligate dominants on the studied area of the Kuzokotsky Peninsula (Fig.1) is characterized by a concentration in three small settlements, the largest of them with 31 nests. Under more favorable conditions, the species studied can form settlements consisting of one hundred or more nests (Otto, 1962; Gösswald, 1978; Goryunov, 2007; Zakharov, 2015). The anthills of F. exsecta on the peninsula are relatively average in size. Both large and small (up to $25 \mathrm{~cm}$ in diameter) nests are extremely rare. According to the classification of Goryunov
(2007), such a structure corresponds to the initial stage of development of complex settlement in F.exsecta. The largest aggregation of F. lugubris nests on the Kuzokotsky Peninsula is a group that consists of a maternal nest and two daughter nests. Such colonies may be located remotely from other species, or be part of multispecies settlements. All the observed nests of F. aquilonia form a cluster of 10 nests in the Cape settlement (Fig. 1).

Abiotic factors have a great influence on the formation of communities in extreme conditions, therefore their structure differ from that of the communities that develop under less severe conditions (Berman et al., 2010). In our study area, the formation of more complex and large single-species settlement is prevented by both abiotic (extreme weather conditions) and biotic (competition with other obligate dominants, permanent destruction of the nests by bears (Table 2)) factors. The peculiarity of the climate on the islands at the Kuzokotskaya Guba is instability, sharp weather variability, associated with the movements of areas of low atmospheric pressure. Therefore, with the background of mild average monthly temperatures (in July-August $+11-14{ }^{\circ} \mathrm{C}$, in December-February - 9-12 $\mathrm{C}$ ), short-term, but strong cooling and warming waves are observed here in all seasons of the year. In winter, the temperature can rise up to $+7{ }^{\circ} \mathrm{C}$ and drop down to $-41^{\circ} \mathrm{C}$ on some days. In summer, the air can warm up to $+30-32^{\circ} \mathrm{C}$, but nevertheless, even in July frosts up to $-1{ }^{\circ} \mathrm{C}$ are possible (Karpovich, 1988).

When the colonies of several obligate dominant species cohabit in a settlement, representatives of each species, as a rule, form clusters (Zakharov, 1977, 2015). "The strategy of population concentration" is also implemented when permanently repeated large-scale destruction of anthills in settlements occurs (Zakharov, 2011a, 2011b). Clusters of nests of several Formica species in one settlement is a characteristic feature of the distribution of ants on the peninsula. However, only F. aquilonia form continuous cluster. The species F. lugubris and F. exsecta form close associations (Fig. 2 and 3), which structural features are discussed below.

The observed association between F.lugubris and F. exsecta is unique because in all previous observations, close proximity of obligate dominants occurred at the boundaries of the settlement of one or the other species. As a rule, they were a consequence of the increased density of the settlements (Zakharov, 2015). The settlements described here have maintained their structure during the two years observation period, which indicates the relative constancy of these formations.

In less extreme conditions F. lugubris forms colonies that are several times larger than the maximum size of those of F.excecta (Zakharov et al., 2013). F. lugubris, as a rule, forms large settlements, on the outskirts of which F. exsecta sometimes settles. On the Kuzokotsky Penin- 
sula, there are more nests of F. exsecta than nests of red wood ants. Apparently, F. exsecta is more tolerant to cold winters (Berman et al., 2010) and quickly restores the nest after its destruction, since this ecotone species was initially adapted to such circumstances (Werner et al., 1979; Cherix et al., 1980; Pisarski, 1982; Goryunov, 2015). At the same time, the nests of red wood ants are much smaller on the Kuzokotsky Peninsula than those on the mainland (Zakharov, 2015). Under such conditions, the success rates of F.excecta and F. lugubris are equivalent, which enables them to form aggregations on parity terms.

The distribution of F.lugubris and F. exsecta nests is structurally different within the settlements "Pink Rocks" and "Cape". However, the average distance between nearest neighbour nests is not different between the two settlements. The average difference between nearest neighbour distance in each settlement is small, which shows that ants establish their nest at an equidistant location from the nearest neighbor nest in both settlements. This, in general, is an indication of a uniform nest distribution within compact settlements (Tables 4, 5, Clark-Evans test). This type of distribution is a sign of competition between colonies and is in good agreement with our knowledge of mound-building ant ecology. In fact, the studied species are obligate dominants that establish a territory that they defend actively. Their FAs are protected from the workers of unrelated nests of the same species, which leads to a uniform distribution of the nests in compact settlements. At the same time, a high unevenness of the environment, a difference in microhabitat conditions, can lead to the formation of settlements in which several groups of compactly located nests are located in the most favorable habitats and are distributed in a uniform manner within each of these groups. We see this situation in the "Cape" settlement: the Clark and Evans test reflects the general nature of the nest distribution in the whole settlement and a small spreading of the distances to nearest neighbor nests, indicating a uniform distribution within the groups of nests.

It should be noted that in the "Cape" settlement the distance between neighbors is almost half that in the central fragment of the "Pink Rocks" settlement (Table 4). This may be due to biotic differences. Obligate dominants in the Kuzokotsky Peninsula occupy well-heated rocky areas, crowberry beds and the marginal areas of moist environments. The preferred habitats for moundbuilding ants in the peninsula are rocks with coniferous species and shrubs. F. exsecta forms single-species settlements (for example, the settlement "Kuzyaki") exclusively on rocks. F. aquilonia is found only on rocky outcrops in the "Cape" settlement. The coastal crowberry beds is a tundra-like type of vegetation (Breslina, 1987) that grows on primitive thin soils on a rocky base (Vital, 2003).
On the mainland, most of the settlement "Cape" corresponds to a rocky biotope. This biotope is surrounded by crowberry beds. The whole rocky surface is occupied by F.aquilonia nests. In the settlement "Cape" colonies of F.exsecta and F. lugubris are located in crowberry beds (Fig. 2). In the settlement "Pink Rocks", in contrary, the nests of these species are located mainly on the rocks and only one nest of each species are located in the crowberry beds (Fig. 3). In the coastal crowberry beds the vegetation where ants can find food forms a continuous cover, representing a more productive biotope (in terms of food supply for ants). This allows the colonies to develop with smaller foraging areas. On the rocks on the other hand, there are many empty rocky areas where ants can find absolutely no food. Ants have to cross these areas to reach depressions in the rock that contain spots of vegetation.

The structure of the settlements in "Pink Rocks" is characterized by an absence of xenophilia (Table 6), i.e. it is relatively unimportant for ants to have a conspecific or heterospecific nest as nearest neighbour. This indicates a random and, as described above, a uniform distribution of nests, although F. lugubris still has a trend towards xenophilia. In the settlement "Cape" it can be shown (Table 6) that F.lugubris colonies are more likely to have F. exsecta nests as closest neighbours than nests of their own species. At the same time, F. exsecta does not show xenophilia. Xenophilia contradicts the tendency for these species to form daughter colonies mainly by means of sociotomy. When new colonies are created by sociotomy, one can expect that conspecific colonies will tend to be closer to each other than to heterospecific ones. The distribution we observed can be explained by the fact that new colonies at a given location are formed mainly by an alternative way and not by budding from a parent colony. Sociotomy can be difficult in extreme conditions. Zakharov and colleagues (2013) calculated that the minimum diameter threshold $(110 \mathrm{~cm})$ required for a nest to form daughter colonies is reached for only about $15 \%$ of the nests of F. lugubris (Fig. 2). In the polar circle region, though, this threshold may differ from the one calculated for more southern populations.

Alternative methods of reproduction include the ability to establish nests using winged individuals by means of temporary social parasitism at randomly chosen Serviformica nests (Dlusskiy, 1967). However, cases of F. lugubris social parasitism on F. exsecta have not been described in the literature. Yet another alternative method of reproduction is the conquest of the weaker competitor's nests, as described above in the "Cape" settlement for a colony of F. lugubris that invaded a colony of F. exsecta. Zakharov (2015) has recently reported a case in which a colony of F.lugubris invaded a nest of F. aquilonia without significant losses, and then invaded a nest of F.exsecta. This could explain the permanent 
presence of F. lugubris in F. exsecta populations, and the similar nearest neighbour distances - F. lugubris could simply be included in the F. exsecta settlement.

Besides their nest, ant colonies have FAs - territories in which they collect food (Kaczmarek 1953). When the nests of different species are close to each other, the matter of interest is the relative position of their FAs (Putyatina 2011). As shown on the map (Fig. 3), the FAs of F.aquilonia are never directly bordered by the FAs of F. lugubris. There are always FAs of F. exsecta between them.

Taking into consideration the uniform distribution of the nests in multispecies settlements, it is possible to assume that the sizes of their FAs are similar. However, an analysis of the size of the FA shows that the size of F. exsecta FAs is about ten times smaller than that of F. lugubris (Table 8). If we take into account our preliminary observations showing that FA of such a small size is also characteristic of the nests located outside mixed F. exsecta settlements, this means that this species feels well in the crowberry beds on the "Cape" settlement. However, the FAs of F. lugubris in this settlement are significantly smaller than in the "Pink Rocks" settlement. This again confirms the assumption that F. lugubris is forced to integrate established F. exsecta settlements.

In the "Pink Rocks" settlement the "integration" of F. lugubris nests within F. exsecta settlement is probably in a more advanced stage than in the "Cape" settlement. One can assume that F.lugubris was already present in the settlement for a long time, and that it occupies a significant part of the territory, probably after invading F. exsecta nests. This is why "xenophilia" in this settlement remains only in the form of a trend. Attention should be drawn to the fact that in the "Cape" settlement all the nests of F. lugubris are single, while in the "Pink Rocks" settlement there are aggregations of maternal and daughter colonies (Fig. 2, 3), which may indicate both a longer presence of F.lugubris in this settlement and more favourable conditions. The uniform distribution of F. lugubris and F. exsecta nests, in spite of the significant difference in the size of their FAs, can also occur due to the alternation of species in the settlement caused by random factors.

Further study of joint settlements of obligate dominant species can open new perspectives in understanding the interactions among ants of this hierarchical rank.

\section{Acknowledgments}

We are grateful to Elena B. Naimark for her help in collecting the material.

\section{References}

Berman, D.l., Alfimov, A. V., Zhigulskaya, Z. A., Leirikh, A. N. 2010. Overwintering and cold-hardiness of ants in the Northeast of Asia. Sofia-Moscow: Pensoft Publishers, 294 pp.
Breslina, I. P. 1987. Rasteniya i vodoplavayuschie ptitsyi morskih ostrovov Kolskoy Subarktiki [Plants and waterfowl of sea islands of the Kola Subarctic region]. Leningrad. $199 \mathrm{pp}$.

Cherix, D. 1980. A preliminary note about structure, phenology, and diet of a super-colony of Formica lugubris. Insectes Sociaux 27: 226-236.

Cherix, D., Werner, P., Catzeflis F. 1980. Organisation spatiale d'un système polycalique chez Formica (Coptoformica) exsecta Nyl. (Hymenoptera Formicidae). Bulletin de la. Société Entomologique Suisse 53: 163-171.

Clark, P. J., Evans, F. C. 1954. Distance to nearest neighbour as as a measure of spatial relationships in population. Ecology 35: 445-453. doi: 10.2307/1931034

Czechowski, W., Radchenko, A. 2006. Do permanently mixed colonies of wood ants (Hymenoptera, Formicidae) really exist? Annales Zoologici 56: 667-673. doi: 10.3161/000345406779508598

Czechowski, W., Radchenko, A., Czechowska, W. 2002. The ants (Hymenoptera, Formicidae) of Poland. Warsaw, Museum and Institute of Zoology, Polish Academy of Sciences. 200 pp.

Dlussky, G. M. 1967. Muravi roda Formica [Ants of the genus Formica]. Moscow, Nauka, 236 pp.

Domisch, T., Finer, L., Jurgensen, M. F. 2005. Red wood ants mound densities in managed boreal forests. Annales Zoologici Fennici 42:277-282.

Frouz, J., Rybnicek, M., Cudlin, P., Chmelikova, E. 2008. Influence of the wood ant, Formica polyctena, on soil nutrient and the spruce tree growth. Journal of Applied Entomology 132: 281-284. doi: 10.1111/j.1439-0418.2008.01285.x

Gorb, S. N., Gorb, E. V. 1999. Effects of ant species composition on seed removal in deciduous forest in eastern Europe. Oikos 84: 110-118. doi: 10.2307/3546871

Goryunov, D. N. 2007. Formyi organizatsii poseleniy u muravev Formica exsecta. [Forms of settlement organization in Formica exsecta ants]. Uspekhi Sovrem. Biol. 127: 203-208.

Goryunov, D. N. 2011. Territorial strategies in ants. Entomological Review 91: 212-220. doi: 10.1134/ S0013873811020096

Goryunov, D. N.2015. Nest-building in ants Formica exsecta (Hymenoptera, Formicidae). Entomological Review 95: 953. doi: 10.1134/S0013873815080035

Gösswald, K. 1978. Waldameisen-Vermehrung durch Bildung von Ablegern. Waldhygiene 9: 1-16.

Hölldobler B., Wilson E. O. 1990. The Ants. Springer, Berlin, 732 pp. doi: 10.1046/j.1420-9101.1992.5010169.x

Hölldobler B., Wilson E.O.2008. The Superorganisms. The Beauty, Elegance and Strangeness of Insect Societies. W.W. Norton, New York. 522 pp. doi: 10.1653/024.092.0324

Kaczmarek W. 1953. Badania nad zespolami mrowek lesnych. Ecol. Pol. 1: 69-96.

Karpovich V. N. 1988. Kandalakshskiy zapovednik [Kandalaksha Nature Reserve]. Reserves of the USSR. Reserves of the European Part of the RSFSR. Moscow, Mysl' I: 20-60.

Kilpelainen J., Punttila P., Sundstrom L., Niemela P., Finer L. 2005. Forest stand structure, site type and distribution of ant mound in boreal forests in Finland in the 1950s. Annales Zoologici Fennici 42:243-258.

Otto D. 1962. Die roten Waldameisen. Wittenberg, Germany. $152 \mathrm{~S}$.

Pamilo, P., Chautems D., Cherix D. 1992. Genetic differentiation of disjunct populations of the ants Formica aquilonia and Formica lugubris in Europe. Insectes Sociaux 39: 15-29. doi: 10.1007/BF01240528 
Pisarski, B. 1982. Structure et organisation des colonies polycaliques de Formica (Coptoformica) exsecta Nyl. Memorabilia Zool. 38: 273-280.

Putyatina, T. S. 2011. The behavior of ants of different species during joint foraging. Entomological Review. 87: 650 657. doi: 10.1134/S001387381102014X

Reznikova, Z. I. 1983. Mezhvidovyie otnosheniya u muravev [Interspecific relations in ants]. Nauka, Novosibirsk. 206 pp.

Vepsäläinen, K., Savolainen, R. . 1990. The effect of interference by Formicine ants on the foraging of Myrmica. Journal of Animal Ecology. 59: 643-654. doi: 10.2307/4886

Vital, A. D. 2003. Rastitelnost ostrovov Kuzokotskoy Gubyi [Vegetation of Kuzokotsky Lip islands]. Pp. 41-49 in Works of the MSU White Sea biological station.

Werner, P., F. Catzeflis, and D. Cherix. 1979. A propos du polycalisme chez Formica (Coptoformica) exsecta Nyl., pp. 115-126. In D. Cherix (ed.), Ecologie des insectes sociaux. UIEIS Section française, Laussanne, Switzerland.

Zakharov, A. A. 1977. Adaptatsii semi muravev k usloviyam obitaniya [Adaptations of ant colony to living condi- tions], pp. 61-81. In M. S. Ghilarov (ed.), Adaptatsii pochvennykh zhivotnykh $k$ usloviyam sredy [Adaptations of soil animals to environmental conditions]. Nauka, Moscow, Russia.

Zakharov, A.A.1991. Organizatsiya soobschestv u muravev [The organization of ant communities]. Moscow, Nauka. $278 \mathrm{pp}$.

Zakharov, A. A. 2011a. Monogyny and polygyny in ant-hill life. Russian Entomological Journal 20: 341-344.

Zakharov, A. A. 2011b. Muravi: strategiya kontsentratsii naseleniya [Ants: the strategy of population concentration]. Zhurnal Obshchei Biologii 72: 269-283.

Zakharov, A. A. 2015. Muravi lesnyih soobschestv, ih zhizn i rol $v$ lesu [Ants of forest communities, their life and role in the forest]. KMK Scientific Press, Moscow. 404 pp.

Zakharov, A.A., G. M.Dlussky, D. N. Goryunov, A. V. Gilev, V. A. Zryanin, E. B. Fedoseeva, E. A. Gorokhovskaya, and A. G. Radchenko. 2013. Monitoring muravev Formika [Monitoring of Formica ants]. KMK Scientific Press, Moscow, Russia. 99 pp. 